\title{
The TPOA Telecentre: A Community Sustainable Telecentre Architecture
}

\author{
Chong Eng Tan $^{1}$, Poline Bala ${ }^{2}$, Sei Ping Lau ${ }^{3}$, Siew Mooi Wong ${ }^{4}$ \\ Institute of Social Informatics and Technological Innovations ${ }^{1,2,4}$ \\ Faculty of Computer Science and Information Technology ${ }^{3}$ \\ Universiti Malaysia Sarawak, Kota Samarahan, Malaysia
}

\begin{abstract}
This paper presented the telecentre implementation for the Orang Asli villages in remote rural areas under the Telecentre Program for Orang Asli (TPOA). TPOA telecentre architecture aims to assist the achievement of a rural community sustainable telecentre through innovation and strategic adoption of ICT technology. Lessons learned from our past telecentre experience have outlined various challenges in the technical aspects of the telecentre implementation and operation. The TPOA telecentre ICT architecture has been designed to address the outlined issues hence producing a smoother telecentre operation that enables the rural communities to selfsustain their own telecentres. The technical support for the remote rural telecentre can be very expensive and impractical due to the extreme physical access condition. Hence, the rural communities themselves have to carry out the support and maintenance to sustain the operation of the telecentre. The TPOA telecentre architecture has enabled a relatively friendly to operate ICT platform in order to assist and make it possible for the Orang Asli to sustain, support, and maintain the telecentre operation.
\end{abstract}

Keywords-Telecentre; sustainability; TPOA; telecentre architecture; ICT4D; rural development

\section{INTRODUCTION}

Telecentre has been a recognized model for bridging the digital divide that encourages the use of ICT tools as the medium to access resources beyond physical reach. The telecentre is particularly important to remote rural communities on social development. The telecentre model implemented in Malaysia started as early as 2002 in the Kelabit Highland of Bario, Sarawak called the eBario Telecentre, followed by the replication of the eBario Telecentre model for other remote rural communities in Long Lamai, Ba’Kelalan, Buayan, and Larapan. Since the implementation of eBario, the telecentre ICT architecture has evolved and improved based on lessons learned along the way. The telecentre model covers a much wider scope beyond its associated physical ICT systems and services. Telecentre's roles and programs, sustainability, and the social issues of the community it serves are among the important factors in overall telecentre development. Telecentre comes in many forms and different names in different countries to serve some special needs of the rural communities. In this paper, we focus on the technological development of the telecentres and showcase our recent telecentre implementations for the Orang Asli communities situated in the remote rural of Peninsular Malaysia. The Telecentre Program for Orang Asli (TPOA) was the third-generation telecentre implementation after the eBario telecentre and the second-generation eLamai, eBa'Kelalan, eBuayan and eLarapan by researchers from the Universiti Malaysia Sarawak (UNIMAS). Experiences gained from the previous telecentre implementations have laid a strong foundation to continue to innovate the ICT technology used for TPOA telecentres.

The TPOA telecentre implementations have moved the ICT team to innovate new ICT architecture that would overcome some of the limitations and shortcomings encountered in the past telecentre implementations. It is crucial to review these technical challenges which will act as fundamental expectations for the next telecentre implementation. All these challenges have direct and indirect impacts toward telecentre sustainability especially for telecentres in remote rural areas that do not have a lot of local resources and the luxury to receive lots of physical technical support from the urban.

The TPOA telecentre architecture is designed to increase its technical sustainability allowing the local community to selfsustain the telecentre. Design considerations that have been taken into consideration include energy efficiency of ICT equipment, friendly user experience, gentle learning curve, ICT system robustness, seamless device interoperability, reduce dependency on Internet bandwidth, and protection against negative impacts of the digital revolution that brought in together through the telecentre implementation. Innovated from the list of considerations, the TPOA telecentre architecture and its ICT components are presented.

The setup and operation methodology of the telecentre is crucial to influence the long-term sustainability of the telecentre in remote rural areas. An effective setup approach and operation mechanism will strengthen the concept of community-driven and community sustained telecentre. Important concepts such as the sense of belonging, the community elected management committee and caretakers, community-driven operation schedule, and community communal work towards self-sustainability were adopted to further promote community sustainable telecentre.

Lastly, the proposed TPOA telecentre architecture was to strengthen telecentre sustainability, especially by the Orang Asli communities. Although the ultimate telecentre sustainability is affected by a wider scope of other factors, we are playing our part to add more values to its sustainability through ICT innovations. 


\section{BACKGROUND}

Telecentre has been widely recognized as the tool for bridging the digital divide. ICT technologies have enabled a wide variety of services to act as a catalyst to accelerate rural social development. Various telecentre models have been proposed and implemented across the world for different domestic conditions and the availability of telecommunication infrastructure. The benefits and positive impacts of implementing telecentre for rural development are undeniable but there are still plenty of challenges to overcome in order to make the telecentre more effective in achieving its goals. After all, there are still $44 \%$ of the world population still living in rural areas according to the World Bank data in 2019 [1].

Many studies have been conducted on the effective Internet access option through the advancement of telecommunication technologies, the various telecentre services for a wider scope of applications in development, and as well as various telecentre sustainability issues. Besides, the effectiveness of telecentre in serving its roles and how telecentre can play a new role alongside the wave of development, are amongst the on-going studies [2]-[7].

Owing to the difficult physical access and lack of local resources in the rural areas, the use of ICT and telecommunication technology are the key to bridge the inequality. The definition of rural areas differs from country to country mainly based on the population size per square kilometer. Wiggins and Proctor [8] further categorized rural areas into three different sub-categories, namely Peri-Urban, Middle rural, and Remote rural, where the further the distance from the urban centres, the less economic advantage hence being considered as more rural. In this case, the remote rural is the furthest to reach with the least economic activities. This paper focuses on TPOA telecentre implementations at the remote Orang Asli villages, our discussion will be specifically on the telecentre implementations in the remote rural areas. Some of the common characteristics of remote Orang Asli villages include extremely difficult off-road access of $30 \mathrm{~km}$ to $60 \mathrm{~km}$, completely without electrical power supply, no means of any communication, and the majority of the villagers are low in literacy or never see a computer in their life. The offroad access is only possible via 4WD vehicles and during the rainy season, landslide and broken bridges may cut off the access road for weeks or even months. Hence, erecting telecentre in the mentioned Orang Asli villages is not only physically challenging but the low literacy level will certainly impose another level of challenge to the introduction of technology and its adoption in the community. The difficult physical access to the remote telecentre sites has imposed a very tough on-site support coming from the urban.

\section{A. Telecentre Evolution}

We are reviewing some of the prior telecentre initiatives particularly in Malaysia owing to most of them share similar characteristics as the TPOA telecentre implementation. The advancement in the telecentre ICT model throughout the years will certainly set a reference guideline for future government adoption on bridging the digital divide. The eBario telecentre implemented in 2002 [9] has set a successful telecentre model for Malaysia. The eBario initiative has sparked social-economy development in the rural village, Bario and the impact of the telecentre can still be noticed even until now although the eBario telecentre has eventually disappeared and has changed its form to serve a different role under the wave of development. The impact of the telecentre is so promising until later in 2007, a few more telecentres were initiated for other remote rural communities through the replication of the eBario successful model [9], [10]. The five telecentre sites under the telecentre replication program include eLamai, eBa'Kelalan, eBuayan, eLarapan and eBario itself as eBario 2.0 [11]. During the same period, several types of telecentres have been initiated throughout Malaysia, namely Universal Service Provision (USP), Rural Internet Center (RIC), Medan Infodesa (MID), USP Communications Center (UCC), Rural Broadband Library, etc. [12]. It is worth noting that most of the widely deployed telecentres were not located in remote rural areas but more in middle rural and peri-urban areas which are relatively relaxed in local resources such as consistent electricity supply, good road access, and more Internet connection options.

The eBario telecentre model in its early day consists of 10 desktop computers and a VSAT satellite gateway that provides Internet access as well as public telephony service. The eBario telecentre architecture is shown in Fig. 1 [13]. The telecentre was powered by a diesel power generator then changed to solar-diesel hybrid and at a later stage into fully solar-powered. The change in the power supply system was due to the inconsistency supply of diesel fuel into the remote rural and also the hiked of fuel price. The telecentre experienced technical issues where it still suffered from the inconsistent solar power supply which prevented it to operate continuously. The occasion shortage of power supply was caused by the design capacity of the system failed to cope with the weather condition in the Kelabit highland. The battery banks were not charged in time to provide power to the telecentre [14].

Under the eBario model replication to other remote communities, the ICT equipment power consumptions have been taken into consideration hence lower power requirement mini desktop and laptop computers have been adopted. Other equipment such as the projector and printer were also adopting a lower power model. This would have eased the issue of insufficient power as experienced in the eBario telecentre. With a lower power requirement, the bad weather condition would not affect the solar power system too much hence avoiding power blackout at the telecentre. In the same period, the eBario computing systems also undergone an upgrade to adopt low power mini desktops and laptops. The awareness on the impact of power requirement towards the operation sustainability has caused a reduction in computer system power requirement, from $300 \mathrm{~W}$ per computer down to $50 \mathrm{~W}$ per desktop and 30W per laptop. The decision on changing the computer model has created plenty of power reserved for the telecentre. The telecentres did not experience much power supply inconsistency problem until five years later when the battery banks reached the end of its usable lifespan. This had shown improvement in the energy efficiency of an ICT architecture has greatly influenced the continuous operation of a telecentre. 


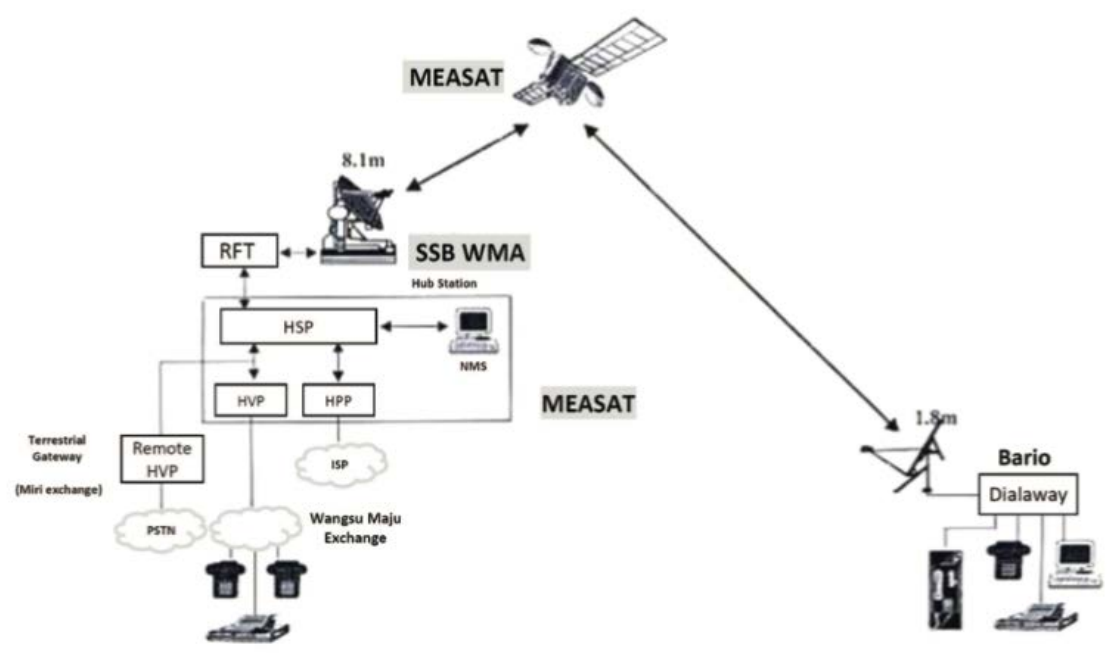

Fig. 1. The eBario Telecentre Architecture [13].

\section{B. Telecentre Sustainability}

The sustainability of a telecentre can be seen from various aspects such as financial, social, operational, policy, and organizational [15] and they are interrelated in the order to achieve the ultimate overall telecentre sustainability. While a large amount of studies focuses on investigating the various factors that affect the telecentre financial sustainability [5], [16]-[18]. In this paper, we will be focusing on the technical operational sustainability of the telecentre instead. From the technology point of view, technology challenges in operation can have a great impact that could result in telecentre failing to fulfill its roles in rural development. Michael highlighted the sustainability failure of SARI project was partly related to the availability of a trained telecentre operator [19]. The telecentre with well-trained operators will sustain a longer period compared to otherwise. Telecentre operational challenges have not gained much attention in the telecentre research because most telecentres have telecentre manager to run the operation when they deprive of trained operators. For the case of telecentre implemented in remote rural areas, the luxury of having a competent team of managers and operators is not always there. Remote rural telecentres' operation is usually run by volunteers coming from the benefiting community itself. External ICT experts will provide technical training to the voluntary future operators during the early stage of telecentre implementation. The natural state of the voluntary operators is that they are just helping to operate the telecentre based on their current capacity which may not be fully competent to perform the tasks.

Over the past two decades, technical challenges in telecentre operation include dealing with computer hardware and software hiccups, guide how to use an application, maintaining ICT equipment that encountered service intermittent, housekeeping the computer operating system in order to keep them in optimum performance state, etc. Failure to handle these technical challenges, the telecentre may not operate at its optimum state to serve its purposes. New users from a remote community with relatively low literacy levels would need a lot of help from the operators in order to learn new technology and demand help when they got stuck with some unfamiliar functionalities. Hence, the task of telecentre operation is not just to open the telecentre so that users can come to use it but also to provide technical assistance. Without competent technical assistance, users may find the telecentre less useful if they do not have the capability to master all knowledge for them to carry out what they wanted. This scenario is particularly true for remote rural telecentres that do not receive a lot of on-site supports from external parties. A community sustained telecentre will experience this a lot because there are very limited competent operators available within the community.

The rural telecentres implemented under the eBario model replication were purely community-driven where there were local champions to lead and manage the telecentre operation. Telecentre operators or caretakers were trained and worked together with the local champions. There have been cases where the trained operators left the telecentre service to attain jobs in the urban or leaving the village, hence under such a situation, activities at the telecentre will be interrupted and the opening hours of the telecentre will also be affected. Besides, any departure of the trained operators will indirectly weaken the telecentre management ability to perform technical maintenance. If such a situation prolongs, the telecentre may slowly become less accessible and lose its role in catalyzing community development. Before personal smart devices become popular, Internet access can only be performed using conventional computer systems. The only means to learn and use digital tools is through the telecentre's computer units. If the telecentre operation cannot keep to its opening hours, the interest and the will to adopt ICT will be discouraged. Such a phenomenon had been observed in a few telecentres and to restore it, a new group of operators need to undergo another round of intensive training conducted by external technologists. Without competent telecentre operators to manage and provide guidance, the computer systems were way too complex for novice villagers to operate. The computer system at the time was a complex desktop system with a relatively complex operating system, the Windows. Although at the time of mention, the telecentres were used for relatively basic applications such as emailing, web surfing, document processing, etc., the telecentre operator's guidance is crucial to 
assist the accomplishment of tasks on these computer systems. Without their help, villagers have been giving their feedback that they still could not operate the computer on their own, owing to ICT is still something very new in their daily routine. The adoption of ICT is subject to the amount of exposure the villagers get from the ICT ecosystem, in order to find out what the technology can do for them. Hence, in a community with very low computer ownership, the consistency of telecentre operation will certainly affect the adoption of ICT among the community members.

Today's ICT world has evolved into personal smart devices that everyone can afford to own one. The digital revolution has changed its form from desktop / portable computing to personal smart appliances such as smartphones and tablet computing. Application software has been shifted from desktop applications to simpler mobile applications. The boom in mobile application development has created a wider variety of features on the smart devices hence there will be more to be learned. The telecentre ICT architecture shall be upgraded to catch up with the new wave of the digital revolution and at the same time to address some of the limitations encountered. The future telecentre architecture will not only have to address some of the technical limitations but also enable a simpler operation and system maintenance to allow easier telecentre sustainability especially those that are sustained by the local community.

\section{THE CHALLENGES}

The telecentre designed for Orang Asli villages will be addressing some of the shortcomings of the previous telecentre implementations in the remote rural areas of East Malaysia. Limitations were being observed from the past telecentre experience hence some of the critical technical issues need to be overcome so that they can be ease in the future telecentre implementations.

\section{A. Unpredictable Power Outage}

In the remote rural environment, there has been no grid electrical power supply hence standalone solar power system has been a very popular choice due to plenty of sunlight available in this region. Even though some may be running on a micro-hydropower system from the river but solar power is a still more flexible and easily available option. The nature of the solar power system is that it has limited capacity subject to the initial design. Owing to this limitation, the power usage of the telecentre cannot go too far beyond the rated supply. If the usage goes beyond the maximum rated power, total system blackout will occur. In a conventional solar power system, the output of the system is usually converted to the standard AC format, in this case, 220VAC. All electrical and ICT appliances were draining power directly from this supply and any power blackout will cause complete telecentre shut down. Even with the adoption of UPS backup power, it will not effective due to its very short backup time and not economical in long run. With the convenient 220VAC standard output supply, many other unplanned appliances can be plugged into the solar power system hence putting the power system at a higher risk of overloading. Designing a higher capacity of solar power systems with higher reserve capacity may be seen as a solution but it incurs much higher initial capital investment. Again, no matter how much additional power capacity is being provided, they still have their limit and this limit can always be breached as long as the usage is not controlled or regulated. Furthermore, the actual capacity of a solar system is greatly influenced by the weather condition, for the same amount of usage under the rainy season, the power system could still be overloaded. It is not wise to put the users to the blame on unplanned usage that could cause unpredictable power outage at the telecentre, a clever power system design would have either prevented or minimized the occurrence of such a situation. The unpredictable power outage problem is not a design problem but more of an operational mismatch that could happen at any time if the power usage is not being carefully monitored. From our experiences with telecentres for eBario, eLamai, eBa'Kelalan, and eLarapan which are powered by standalone solar power systems, the unpredictable power outage issue is common and has been distracting telecentre services from time to time. The telecentre power supply architecture shall be redesigned to minimize the outage issues.

\section{B. Fragile End user Computer System}

The computer system is the interface of computing experience for end-users. Users would need to familiar with all the computer system components such as the CPU unit, the monitor, the keyboard, the mouse, etc. The majority of the telecentre users are rural folks who have very little experience dealing with the relatively advanced computer system. Their experience with computer systems is a novice and only know using the computer system as it is, as what they have been taught on how to operate them. The steps of operation given can be as clear and precise but things do not always turn up the same way all the time. Faulty component, loose connection, and missing operating steps are common problems in daily computing experience that require basic troubleshooting skills to solve. But for the user group that makes up the majority of the rural community, such simple problems can be the cut-off points that stop them from using the computer systems. In our experience, many computer systems in the telecentre being labeled as "broken" were actually "usable" by performing some simple or common sensed troubleshooting. The solution may look straightforward but due to the large knowledge and experience gap between the urban and rural, the rural telecentre users were bog down by very simple problems that in the eyes of many urban folks, are not a problem at all. For example, a loose power connector, monitor cable, keyboard, or mouse could cause a problem and stop them from using the computer system. The standard computer system with multiple components connecting to each other for it to work is too complex to manage and to troubleshoot especially for someone who just wants to use for simple Internet browsing. To achieve interrupt free computer usage, the users will have a lot more to catch up, learning how to deal with computer components resulting in a steeper learning curve in order to be effective in using a computer system. A more robust end-user computer system is crucial for rural telecentre especially since the majority of users have relatively low computer literacy.

\section{Inconsistent Application Experience}

Software applications are the actual ICT tools to enable ICT services in a computer system. Similar to the problem of computer system components and hardware, inconsistent 
software application behavior will certainly produce situations users never seen before and unable to handle. There is no way for users to learn and see every behavior of all software applications. Our past telecentres were adopting a corporategrade Microsoft operating platform with Office tools and other Internet browsing applications. No doubt the operating platform is feature-rich and sufficiently powerful in handling decent computing needs, but the highly dynamic and flexible platform is also a foe to the rural users. To perform a simple function, there may be tens of options to choose from and users can get very confused, and sometimes they do get pop-up windows that asking them questions that they do not know how to answer and how to proceed from there. Even during system boot-up, unexpected pop-up windows may have paused the start-up process and asking users to choose "OK" or "Cancel" in order to proceed. Without having enough knowledge to understand what the pop-up window is asking for, some users do not even dare to make the choice, worry that they might cause damage to the computer system. Many such scenarios in our experience, users chose to turn off the computer system and labeled it as unusable or broken. They will not touch the computer system until the so-called problem of pop-up windows being rectified by technical personnel. The situation turned worse if there were no competent technical support onsite to rectify the issue, the computer system could stay idle for months without anyone using it. Sadly, the pop-up window could be just a casual reporting message from the operating system and because the message sounded technical, it could be treated by users as the system is having a problem or broken. Hence, the application experience shall be made as consistent as possible to avoid confusion and increase productivity.

\section{Complex and Steep Learning Curve}

The combination of a conventional desktop computer system with a modern desktop operating system such as the Windows operating platform, can be very complicated and having a steep learning curve. For the users to be able to use the computer system as a tool for their purposes, they have to first master the operating of the computer system as well as all the associated operating system features. Without understanding the process flow and features of the operating environment, users may not be able to make good use of this digital tool to assist them in their communication, learning, information gathering, and productivities. Owing to the steep learning curve, the growth of the digital adoption rate through the use of a conventional computer system could be relatively slow. Hence, instead of making the users learn more about the digital tools before they can use the tools effectively, it would be much relaxed if the computing system can be made or designed with much gentle learning curve for faster and less stressful adoption.

\section{E. Lack of Competent On-site Technical Support}

The biggest problem of technology deployment in rural areas is the lack of competent technical support personnel onsite. Technology deployment is a relatively new thing to many rural communities, the knowledge, and experience of local support is always lacking. Technical training can be provided to develop the local human capital in technical support but it takes time and experience for technical personnel to become competent. The challenge of training the local technical support is not only time consuming but the high turn-over rate of trained technical personnel has put the effort of earlier training back to square one. From our experience, the high turn-over rate was due to trained personnel leaving the village for other jobs in town. The telecentre technical support shall be made as less technical as possible so that a telecentre caretaker can easily acquire the knowledge to carry out the task of technical support.

\section{F. Lack of Autonomous Service Monitoring}

For many rural areas, the only communication means to the outside world is through the telecentre Internet gateway. In rural areas of Malaysia, most rural telecentres utilize the VSAT satellite connection for Internet access and telephony. This is due to satellite coverage that cannot be blocked by any on land obstacles such as mountain and thick forest. Regardless of how remote the telecentre is, as long as there is good sky visibility, the VSAT connection will be able to bridge the communication gap. The problem is, any failure of VSAT equipment or service interruption caused by local equipment, will cut off all communication between the telecentre and the outside world. This including there will be no way to file a complaint on equipment fault and request for technical support from the VSAT operation team. When the issue of such is happening, someone from the local community shall be traveling to the nearest town in order to file a fault report. For rural villages that are extremely remote, it may take months until someone is making a trip to the nearby town and make that fault complaint. During the fault period of critical equipment, the telecentre ICT services will be completely cut off and made redundant. Under normal circumstances, it is difficult for the VSAT service operator to detect the faulty equipment through a link down indicator status because a VSAT link down could be due to a temporary power outage or the equipment being shut down on purpose. The VSAT operator will not send the technical support team until they received an official complaint from the users. Our experience with telecentres, the VSAT service outage could persist up to a few months without being noticed until the problem is reported to the VSAT support team. Such a long period of communication outage has defeated the primary purpose of a telecentre to act as a communication hub to bridge the digital divide in the rural areas. Owing to that, the communication link monitoring mechanism is essential in order to keep the telecentre to its maximum service uptime.

\section{TPOA TELECENTRE DESIGN PHILOSOPHY}

\section{A. The Mission of TPOA}

TPOA is the Telecentre Program for Orang Asli project started in 2013 with prior engagement with Orang Asli as early as 2011 on the need analysis. Telecentres have been implemented at four remote Orang Asli communities in Peninsular Malaysia namely Pos Sinderut and Pos Lenjang at Pahang state, Pos Gob and Pos Balar at Kelantan state. The project was a collaboration with the Department for Development of Orang Asli (JAKOA). The main objectives were to facilitate communication, provide access to information, create resource centres for new knowledge and skills, provide education through ICT, provide training for local capacity building, provide health-related information to 
villagers, and drive rural development through the telecentres as Rural Transformation Centres through the execution of the six telecentre programs; Agribusiness, Eco-tourism, Education, Health, Indigenous Knowledge and ICT Training [20].

Apart from serving the in-house telecentre programs under the TPOA project, the telecentre should also serve the local community in aspects where deem needed. In the era of the rapid growth of smart mobile communication, more people own smart mobile devices than conventional computing devices and the growth of personal smart devices among the Orang Asli community has also increased over years. The TPOA telecentre would need to expand its coverage scope to accommodate the demand of WiFi connection for Internet access as well as facilitating more socio-economic activities. The smart devices enable personal communication with the outside world, allowing more exchange of information on matters of personal and community interest. At some of the TPOA telecentre sites, the service of charging the community smart devices and the power bank has to be provided as many do not have access to the electricity supply. Hence, the TPOA telecentre is no longer just providing resources to serve inhouse programs and equipment but also acts as a community communication hub and power supply centre. On the other hand, the increased ownership of personal smart devices among the local community could be directly or indirectly due to the availability of WiFi Internet connection provided by the telecentre, hence accelerated the local digital adoption rate. Since the full deployment of TPOA telecentres in 2017, apart from visiting the telecentre for its programs, the telecentre has become a daily visit place for the local community to pick up and send their personal messages over WhatsApp and WeChat. Some even make use of the messaging platform to raise and discuss cases on community land rights issues, to contact buyers for their farm products, and also to arrange with visitors coming to the village.

\section{B. The Telecentre Design Philosophy}

Sustainability is a key element in TPOA telecentre for remote Orang Asli communities. Looking from the past telecentre experience, telecentre implementation in its early stage can be relatively relaxed as everything is still brand new and less of a problem. When the telecentre goes on for a few years, more and more maintenances are required until a point where the telecentre may require equipment refresh in order to continue its existing role or be upgraded to serve a new function. The transition in community needs is taking time subject to how soon they get used to existing technology and be ready to move on to higher-level applications. This transition could take many years to happen hence the deployed telecentre ICT systems should last as long as possible until their service is no longer required. It is undeniable that some system parts will wear out with time and shall be maintained or replaced throughout its service life, but with additional considerations on maintenance, the overall telecentre service lifespan can be sustained and prolong. Hence, the telecentre ICT system architecture plays an important role to enable greater sustainability with minimal expenditures. More importantly, the telecentre at the end of the day, ideally shall be sustainable by the community itself within their financial capability instead of waiting for new large funding to refresh the entire telecentre. Some older telecentres are way too expensive to be self-sustained by the community owing to the components to be replaced are beyond the community financial capability. With TPOA telecentres, the ICT systems have been optimized in order to achieve more community-friendly sustainability. The TPOA telecentre architecture focuses on improving the following aspects.

\section{Energy Efficiency}

The energy supply for remote telecentre is extremely critical as all equipment depends on it to operate. On a single large power supply system such as a standalone solar power system, once the power supply system is interrupted for whatever reasons, the telecentre will be shut off completely. Instead of providing an even larger power supply system, which is much more costly, we look into optimizing the ICT systems' power requirement to minimize the use of power and reduce the overall power expectation. ICT equipment with lower power requirements shall be carefully adopted. Also, instead of using one single large power supply system, multiple smaller independent power supply systems can be implemented to reduce the risk of putting all eggs in a single basket, but to dedicate independent power supply for different equipment based on their criticality. Hence, segregating critical equipment from being affected by power supply failure at other parts of the telecentre. Portable and mobile computing devices that come with their internal battery system shall be adopted to reduce the dependency on the always-on power supply in order to operate.

\section{User Experience}

The user experience of using the telecentre systems and services is crucial in determining the acceptance of technology in the community. Not everyone is technology savvy hence poor user experience in using the technology may put them off and thinking that the ICT skill is too difficult to acquire. A friendly and easy to use ICT system experience will certainly give motivation and confidence to novice users, to give them an impression that the use of ICT technology should be a straightforward process and anyone can learn the skill just like anyone else. A strategic combination of technology will give a better user experience even users with minimal literacy should be able to use it. Hence, user experience is a key expectation when comes to packaging the hardware and software solution for the telecentre. Given an example of poor user experience in urban ICT, connecting a laptop to a client projector for presentation sometime can be frustrating because the technology is supposed to be just plug-and-play but in reality, this never always the case.

\section{E. Gentle Learning Curve}

Adopting ICT technology requires a learning process and the learning curve of any telecentre tools should be as gentle as possible, moreover if the targeted community is low in literacy. ICT technology gets more complicated now but they can be made simple by focusing on the primary purposes the technology serves. By simplifying the ICT systems to serve just only a few relevant functionalities or re-designing the system to allow a simpler operation, would have made the learning curve very gentle. This is particularly important for new learners who have very little exposure to ICT systems and 
services. The mastery of ICT requires a lot of knowledge but ICT is just a tool in the telecentre hence if the operation of the tools can be made simpler without the need to learn the indepth ICT knowledge, then the technology adoption can be less stressful. How to achieve simpler operation and gentle learning, the ICT technology for telecentre shall be adopted strategically and innovatively. The concept of simplicity and gentle learning shall not only applicable to technology operation and learning, but should also apply to technical troubleshooting, for the minimum, to simply the recovery of equipment from operational hiccups. More importantly, the telecentre caretakers can have a higher confidence level in managing the technology and provide training. The training of new caretakers can also be done by the existing caretakers themselves. This shall contribute to telecentre operational sustainability in long run.

\section{F. System Robustness}

The system's robustness refers to its robustness against vandalism. The telecentre equipment that requires a higher level of robustness will be the shared end-user computing devices. From experience, shared end-user devices especially computer systems require frequent housekeeping and maintenance as users like to introduce all sorts of customization, changing some of the system settings, and even exploring every single function of the system. Under such a scenario, many computer systems do not work as expected after a few sessions of usage. Particularly children users, they will explore every corner of the system with their curiosity or even vandalize the system. Hence, end-user appliances should be something that could withstand extreme usage conditions especially maintaining its software functionalities. This is important to reduce the amount of effort in maintaining every piece of the end-user device in order to keep them in working order every day.

\section{G. Seamless Interoperability}

There will be many ICT appliances co-existed in the telecentre where information exchange and sharing of files somehow are unavoidable across devices. Simpler information and file sharing for printing or display on the projector will certainly create a smoother telecentre operation. In many cases, in order to share a file across devices wirelessly, many setup steps and configurations are required, making it a complicated task for telecentre caretakers to manage. Since information and file sharing is a common task, creating a seamless interoperable ICT platform within the telecentre shall ease the process. This seamless operation across devices shall also make the training session or remote conferencing over the projector screen easily accomplish. Setting up ICT devices to work together can be a frustrating task even it looks straightforward in the first place. Many advanced users still occasionally experiencing problems connecting their laptops to a projector for their meeting or presentation. Hence, it is important to minimize the potential hiccup in device interoperability especially for rural telecentre environments with no experienced technical support personnel.

\section{H. Reduce Dependency on Internet Bandwidth}

The telecentre receives all information and data through its Internet connection. In principle, as long as the Internet connection is active, all data can be obtained in digital form, but the case is not always ideal. Most rural telecentre's Internet connection is through the use of VSAT satellite connection, at least it is the case in Malaysia. Owing to it is a long-distance satellite connection, the reliability of connection especially for the Ku-band VSAT is subject to the weather condition and the actual bandwidth available is subject to contention with other VSAT terminals grouped under the same channel for bandwidth sharing. Hence, the Internet experience over the VSAT satellite system is far poorer than the urban fiber-based Internet experience. The VSAT connection is expected to experience fluctuate bandwidth performance throughout the day and this is common nature for a shared data connection with an affordable monthly rate. Hence, knowing the nature of the satellite connection, a 4Mbps Internet link may be meeting the bandwidth requirement of applications such as video streaming over the Internet but the experience could be bad from time to time. Having all applications executed over the Internet connection at all times is not a brilliant idea. This is particularly crucial for the delivery of multimedia-based education content. A new initiative is needed to adapt to the VSAT bandwidth nature and to reduce the full dependency on telecentre Internet bandwidth for all applications.

\section{Protection against Negative Impact of the Digital Revolution}

The introduction of the Internet through the telecentre opens the portal that allows the rural community to reach the rest of the world. The portal can deliver all required information, messages, interaction with other Internet communities, etc. This is a new digital revolution that the rural community never experience before and users can be naïve as not be able to judge between genuine and threat. Furthermore, the attractive social media network can be over additive to some newcomers to the world of the Internet. ICT technology has the ability to connect must also have control over parental new users. Instead of letting them swim on their own in the open sea of the Internet on day one, a guided exploration on the Internet will reduce the negative impact on the rural community. From experience, the widespread of social media has already caused social problems among the rural community hence the implementation of telecentre shall strike a balance between benefits and negative impacts.

\section{TPOA TELECENTRE ARCHITECTURE AND COMPONENTS}

The TPOA telecentre consists of a telecentre building that house all ICT systems, activity area and a $4 \mathrm{~kW}$ standalone solar power system next to it. The full TPOA telecentre program implementation took several years to accomplish because it is not just the telecentre itself but there are many crucial non-technological stages involved such as community need analysis, community engagement, telecentre management committee formation, leaderships and community protocol development which blend the human and technology to achieve the telecentre objectives, bringing greater community development impact through intensive community participatory and lastly, to achieve a full community selfsustain telecentre in its operation. In this paper, we will be focusing on the technology portion of the TPOA implementation which will be on the ICT architecture and its 
components. Adopting different ICT technology under the same roof will certainly experience many technical hiccups especially in device interoperability and operation intermittent. The job of managing and operating a telecentre can be an overwhelming task for inexperienced local caretakers. Hence, a good blend of ICT architecture is crucial to ensure the telecentre can deliver its intended services. The TPOA telecentre ICT architecture aims to provide a simple operating platform for telecentre caretakers and at the same time minimize the effort of technical troubleshooting by proposing a good and strategic combination of software-hardware solution that allows all components to work together seamlessly. Fig. 2 shows the TPOA telecentre components and services.

\section{A. The Modular Power Supply}

As we gained a good understanding of the standalone conventional solar power system's nature and problem, where it may be the single point of failure under overwhelming usage. Unfortunately, we still need the conventional solar power system to provide compatible power supply to some general AC-based appliances, we cannot change the conventional solar power system into a new proprietary standard for our purpose but to adopt additional smaller modular power supply systems as a backup measure. The modular solar power supply module was first introduced in our pilot deployment of the long-range wireless system for extending eBario Internet connection to nearby villages back in 2010 [21] and the modular solar power supply concept is effective in providing isolated solar power for dedicated equipment and yet it is a relatively small solar system. Hence, under the TPOA telecentre design, we have adopted a few modular solar power systems for several more critical equipment in the telecentre. The modular and conventional solar systems run in parallel to support each other in the event of an unpredicted outage. The Modular solar power systems provide backup power for tablet computers recharging, local portal server, and local WiFi network equipment. By having more power supply options some of the services will still be active if the main conventional solar system fails. Owing to the modular solar systems are operated independently, they are not affected by any faults in other power supply systems. The modular solar supply is relatively light-weight and can be easily relocated to a new location for future service that extends beyond the telecentre.

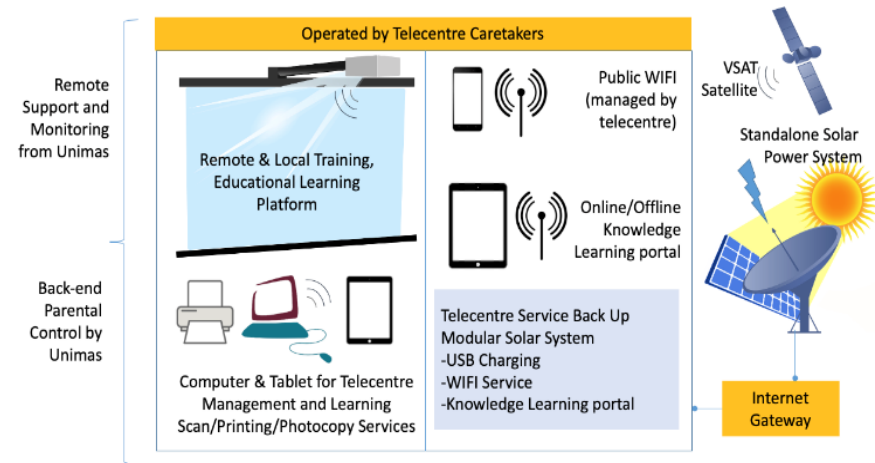

Fig. 2. TPAO Telecentre ICT Components and Services.

\section{B. The Mobile End-User Computing}

The end-user computing device selection is critical as they are to be deployed in large numbers. We have chosen to adopt tablet smart devices as the end-user interface to the ICT applications and the Internet. Tablet computer has the advantage of power supply due to it has a built-in battery with relatively long operating hours before it requires a power recharge. The USB-based charging standard on the device enabled flexibility to be recharged by any universal power source, for example, it can also be charged using the modular solar power charger that delivers USB power output. Tablet computer comes in relatively large screen size, in this case, we have chosen the iPad Mini that comes with close to 8 inches of screen size which is sufficient for most applications. The screen is not larger as to strike a balance to the amount of power required to fully charge the device. The iOS platform is by far the most stable and user-friendly user platform to our standard. It meets our expectations of good user experience and for our in-house developed education app. We also leverage on the parental control feature to impose restriction for making the tablet more robust against out of scope usage and user activities. Others may see adopting iOS devices would increase the cost of implementation as they are generally more expensive but for better device's built quality and the associated iOS platform, it is a strategic provision of technology for a rural telecentre. The iOS devices have met our ICT system expectations on simplicity, robust, seamless interoperability with other devices and parental control. Since the telecentre was implemented in 2016, we have not encountered many issues in maintaining the tablet in working order.

\section{The Local Information Portal}

In order to reduce the dependency of applications on the telecentre Internet bandwidth which is over the limited VSAT satellite connection, we have built a UNIX based microserver to act as a local information portal to serve heavy-weight multimedia contents for the telecentre education applications. The microserver power consumption has been optimized to operate under $20 \mathrm{~W}$ of power and could also be independently powered by the modular solar power supply in the event of the main solar power supply not available. With the contents hosted on the local server, even in the event of an Internet outage, the education contents will still be available for the education program. Owing to the power supply at the telecentre that may not always be stable and blackout may occur unexpectedly, the operating system of the local information portal has been designed and set up in such a way to survive a sudden power cut and boot to its normal operation when the power is back again. The entire recovery process does not require human intervention hence reduce the need for maintenance after a blackout incident. The local information portal also playing the role of synchronizing its contents and acting as an Internet service availability check-point. The local server has been programmed to execute a monitoring and check-in mechanism over the cloud service to allow monitoring of telecentre Internet service from a public network 


\section{The Presentation Platform}

The presentation platform is also known as Remote \& Local Training, cum Education platform which consists of a projector, wall screen, and a TV unit. Its primary purpose is for conducting group training and online group meeting. Both projector and TV were connected to the micro-console digital media player called the AppleTV. The micro-console takes advantage of the AirPlay feature over the WiFi network to allow tablet computers or the management workstation to playback its content to the connected display equipment, in this case, the projector or the TV unit. This seamless display porting from user device to the big screen with only a few taps on the user device has created a wonderful user experience for the telecentre caretakers to conduct training activities, share display, and demonstrate the use of various apps for a bigger group of audience. The front-facing camera of the tablet computer combined with the presentation platform's big-screen display makes up a perfect tool for online conference meetings and online training. The presentation platform allows switching of the display from multiple user devices to share their screen seamlessly has enabled presentation to a big group of audience easier than ever. Regular online meetings and education sessions have been conducted over this platform and the caretakers find it very easy to set up these sessions.

\section{E. The Wireless Network}

The wireless network of the telecentre allows easier integration of the telecentre equipment. It does not only provide Internet access to all authorized telecentre equipment via the WiFi access network but also have to service connection from the personal WiFi devices of the local community. The WiFi network is a convenience to access but its nature is notorious for its quick network performance degradation under an overcrowded situation. We experience a lot of similar situations even in urban WiFi access. Concurrent connections from more than 30 devices to the same access point will certainly cause the performance problem to the WiFi network. The WiFi network needs segregation in terms of the number of connected devices and bandwidth prioritization so that the telecentre internal networked operation will not be affected by the seasonal peak usage coming from the community's personal devices. The public access WiFi is on another dedicated network segment where access control has been implemented for fair usage. Owing to the Internet VSAT gateway has limited bandwidth, and 4Mbps of bandwidth can never be enough for a large group of user access to modern multimedia intensive applications such as YouTube. The regulation on bandwidth usage is crucial to ensure the more critical messaging applications have higher priority access to bandwidth. Telecentre core applications will also be given priority and higher bandwidth allocation, for example, the online real-time conferencing will have higher bandwidth priority than other non-real-time applications.

\section{F. The Management Workstation}

Telecentre services are not limited to end-user usage but also to assist telecentre management such as caretakers to conduct activities, dealing with official paperwork, preparing new content, etc. Another more powerful workstation computer has been allocated for more advanced tasks and applications.
The workstation computer can seamlessly deploy new content such as eBooks and other media onto all the tablet computers via the AirDrop feature. Besides, it has integration with the presentation platform as well for controlling presentation sessions or video playback on the presentation big screen. The workstation housed all training materials in an interactive website hosted locally. New training materials can be synchronized into the workstation via online cloud storage service.

\section{G. The Multi-functional Printer}

The multi-functional printer is an add-on to support local community needs such as to produce hard copies of government application forms, passport photo printing, ID card photocopy, and some other paper-based reports and letters. The multi-functional printer is a low-cost inkjet printer with scanning functionality. The role of the printer is not an essential part of the ICT platform but to provide convenience to meet the needs of many conventional paper-based systems still using in rural areas. The printing is a charged service where the income is used for consumable ink replacement and printing papers. The printer is also a networked printer with WiFi capability to connect to the telecentre WiFi network. Printing of files and photos to the printer is done seamlessly via the AirPrint feature supported under iOS and macOS.

\section{TeleCEnTRE SETUP AND Operation Methodology}

The telecentre setup is not just merely putting up the planned ICT systems in place and get them up running. The setup and building processes of the telecentre play another important role in determining the future sustainability of the telecentre itself. The telecentre building fund is from the Malaysian government hence by impression, the telecentre belongs to the government and the government supposes to take care of it from its operation to maintenance. Unfortunately, for remote rural telecentre projects like TPOA, the funding is usually one-off, meaning the funding is fixed to an allocated amount. The long-term sustainability plan and budget may not be part of the picture but more of a case-bycase basis. Owing to that, the benefiting local community from the telecentre project shall be brought into the picture so that the telecentre will be sustained by the local community as far as the community still needed it. For such a remote rural telecentre, external support is always very expensive and difficult to realize due to the telecentre is too remote. Hence, the telecentre requires local community commitment, participation, and support in order to be sustainable. Several setup and operation methodologies have been used to encourage community participatory so that at the end of the day, the telecentre can be managed, operated, and maintained entirely by the local community.

\section{A. Sense of Belonging}

The involvement of the local community in the building of the telecentre is crucial because their active and voluntary participation will inject a strong sense of belonging towards the telecentre. From the building structural design to the engagement of the local workforce in the construction process, local ideas and efforts will mark the community identity on the telecentre which makes it one of their own. With a strong sense of belonging, the local community will take greater 
responsibility to ensure the safety of the building and also taking more initiatives to maintain it within their capacity. In the remote rural environment with minimum access to external support, telecentre can only be sustained effectively by the commitment of the local community. Fig. 3 shows the unique design of the four TPOA telecentres of Orang Asli at Pos Sinderut, Pos Lenjang, Pos Balar, and Pos Gob respectively representing their unique community identities.

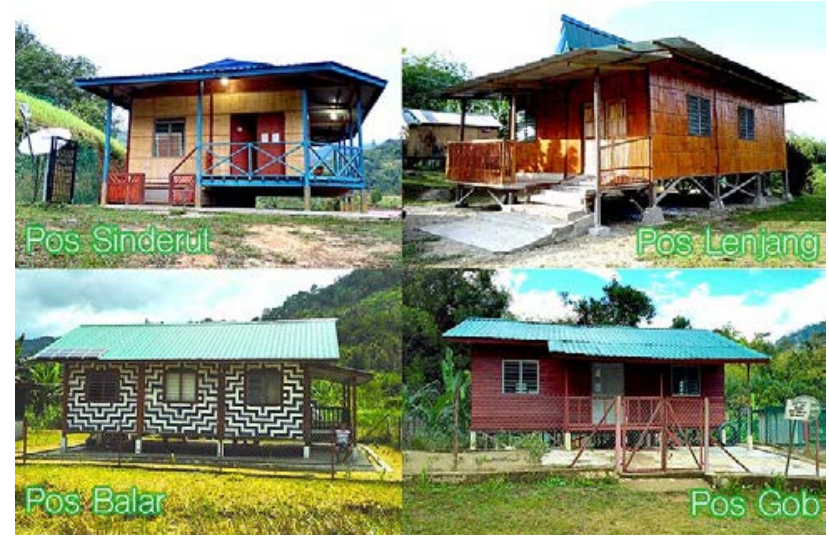

Fig. 3. The Four unique TPOA Telecentre Buildings.

\section{B. Community Elected Telecentre Management Committee and Caretakers}

The telecentre management committee shall be elected from the local community by the community itself. Our team of researchers will only provide guidance on the management skills and operation training so that the management committee together with the trained telecentre caretakers can manage and operate the telecentre services all on their own. This is an important step to cultivate community leadership and building local capacity to teach and educate the entire community. The local management committee will meet to discuss issues encountered and propose new plans to improve the telecentre and to appoint talented community members to succeed any caretakers left so that the telecentre will continue to serve its functions.

\section{Community driven Operation Schedule}

For a community-operated telecentre, the operation schedule shall be designed according to the living style of the respective local community. The urban 8 am to $5 \mathrm{pm}$ schedule just not practical for a community that lives a rural lifestyle. Telecentre caretakers who man the telecentre are usually voluntarily and they have a living to make and a voluntary job at the telecentre should not put them into any difficult situation. Hence, the operation hours and days were to be discussed and decided through a community meeting. The local management committee even requests to stop the open WiFi service after 11 pm so that no community members hang around until midnight to avoid social issues within the community.

\section{Telecentre Maintenance via Communal Work}

The maintenance of the telecentre building and its surrounding requires communal work by the local community at a fixed routine, community members gathered together to clean up and maintain some of the broken pieces of the telecentre building. The solar panels of the telecentre power supply system will require periodic cleaning and this is the time the panels get clean up in order to maintain the performance of the solar power system always at its peak. Hence, the culture of communal work will certainly help in sustaining the telecentre services to its designed lifespan. Fig. 4 shows a routine communal work of cleaning the solar panels.

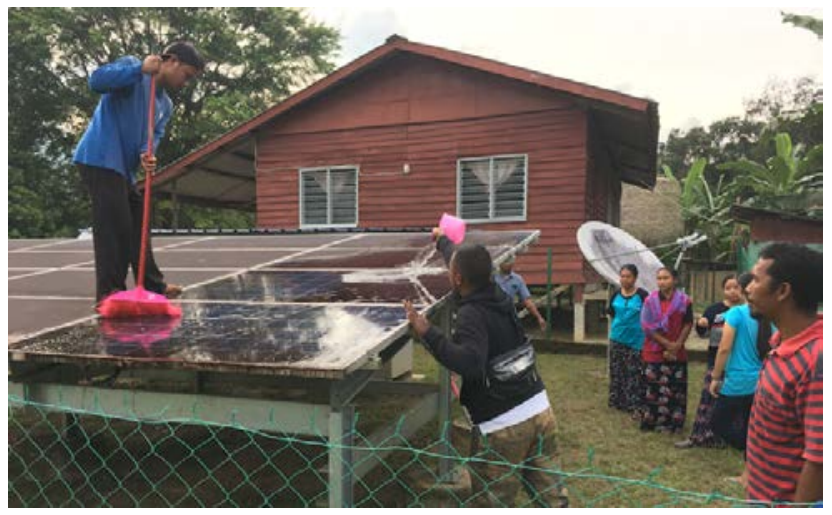

Fig. 4. Routine Communal Work of Cleaning the Solar Panels.

\section{CONCLUSIONS}

In conclusion, we have presented challenges of telecentre implementation learned through 20 years of past telecentre projects where these challenges put up new expectations for future telecentres. The TPOA telecentre implementation is the showcase of the new ICT architecture for telecentre at the Orang Asli villages. Through the new expectations on ICT systems and its associated digital platform, technology has been designed and adopted strategically to assist the rural community to self-sustain the telecentre that brings social and rural development to their communities. The longer the telecentre operation can be sustained, the more rural development could be seen through the telecentre initiatives.

REFERENCES

[1] World Bank, "Rural Population (\% of Total Population)," World Development Indicators 2019, 2019. https://data.worldbank.org/ indicator/SP.RUR.TOTL.ZS (accessed Jul. 20, 2020).

[2] R. Heeks, "Information and Communication Technologies, Poverty and Development,” SSRN Electron. J., 1999, doi: 10.2139/ssm.3477770.

[3] M. K. Bhattarai, "Telecentres in Nepal: lessons learned, prospects and challenges." http://www.ruralict.ftml.net/np/Bhatt.pdf (accessed Jun. 20, 2020).

[4] R. Harris, "Telecentre Sustainability: Financing ICTs for the poor," APDIP eNote 15, p. 0, 2007, [Online]. Available: www.apdip.net/apdipenote/15.pdf.

[5] M. E. K. Mphahlele and M. E. Maepa, "Critical success factors in telecentre sustainability: a case study of six telecentres in the Limpopo Province," Communication, vol. 29, no. 1-2, pp. 218-232, Jan. 2003, doi: 10.1080/02500160308538028.

[6] J. Lee and P. Sparks, "Sustaining a Nepali Telecenter: An Ethnographic Study Using Activity Theory,” Int. J. Educ. Dev. Using Inf. Commun. Technol., vol. 10, no. 2, pp. 41-62, 2014, [Online]. Available: https://ezproxy.bibl.ulaval.ca/login?url=http://search.proquest.com/docvie w/1773225425?accountid=12008.

[7] T. Van Gevelt, "Indigenous communities, ICT and rural development: case studies in Tanzania and Sarawak, Malaysia," no. February, p. 24, 2017.

[8] S. Wiggins and S. Proctor, "How Special Are Rural Areas? The Economic Implications of Location for Rural Development," Dev. Policy Rev., vol. 19, no. 4, pp. 427-436, Dec. 2001, doi: 10.1111/14677679.00142 . 
[9] R. Harris, N. A. N. K. Ramaiyer, and J. Tarawe, "The eBario Story: ICTs for Rural Development," in 2018 International Conference on ICT for Rural Development (IC-ICTRuDev), Oct. 2018, pp. 63-68, doi: 10.1109/ICICTR.2018.8706855.

[10] Universiti Malaysia Sarawak, "ICT for rural communities in Malaysia," Asia Research News, 2007.

[11] A. W. Yeo, F. S. Hazis, T. Zaman, P. Songan, and K. A. Hamid, "Telecentre Replication Initiative in Borneo Malaysia: The CoERI Experience,” Electron. J. Inf. Syst. Dev. Ctries., vol. 50, no. 1, pp. 1-14, Jan. 2012, doi: 10.1002/j.1681-4835.2012.tb00353.x.

[12] N. Razak and J. Malek, "Bridging digital divide in Malaysia: Cyber learning for the marginalized community,” 2008, [Online]. Available: http://www.waseda.jp/DLI2008/program/proceedings/pdf/session9-1.pdf.

[13] Z. Hushairi, A. H. Khairuddin, P. Songan, A. W. Yeo, and J. Gnaniah, "Bridging the Digital Divide - the E-Bario and E-Bedian Telecommunication Framework," in Seventh Conference on Work With Computer Systems, 2004, pp. 277-281.

[14] M. Anyi, B. Kirke, and S. Ali, "Remote community electrification in Sarawak, Malaysia,” Renew. Energy, vol. 35, no. 7, pp. 1609-1613, Jul. 2010, doi: 10.1016/j.renene.2010.01.005.

[15] S. S. B. Shadrach, "Telecentre Sustainability - Misnomers, Challenges, and Opportunities," telecentre.org, no. May, 2011.
[16] H. Ibrahim, A. Yasin, and Z. Md Dahalin, "Financial Sustainability Issues in Malaysia’s Telecentres,” Comput. Inf. Sci., vol. 3, no. 2, Apr. 2010, doi: 10.5539/cis.v3n2p235.

[17] F. Proenza, "Telecenter Sustainability - Myths and Opportunities,” J. Dev. Comm., vol. 12, 2001.

[18] A. Bailey, "Issues Affecting the Social Sustainability of Telecentres in Developing Contexts: A Field Study of Sixteen Telecentres in Jamaica," Electron. J. Inf. Syst. Dev. Ctries., vol. 36, no. 1, pp. 1-18, Jan. 2009, doi: 10.1002/j.1681-4835.2009.tb00251.x.

[19] M. L. Best and R. Kumar, "Sustainability Failures of Rural Telecenters: Challenges from the Sustainable Access in Rural India (SARI) Project," Inf. Technol. Int. Dev., vol. 4, no. 4, pp. 31-45, 2008, doi: 10.1162/itid.2008.00025.

[20] P. Bala and C. E. Tan, Methodologies for Bridging the Digital Divide amongst Remote and Rural Communities in Peninsular Malaysia, 1st ed. Kota Samarahan: UNIMAS Publisher, 2018.

[21] K. Ab-Hamid, C. E. Tan, and S. P. Lau, "Self-sustainable energy efficient long range WiFi network for rural communities," in 2011 IEEE GLOBECOM Workshops (GC Wkshps), Dec. 2011, pp. 1050-1055, doi: 10.1109/GLOCOMW.2011.6162337. 